\title{
Oficinas de Informática e Cidadania: em busca de um modelo de inclusão digital baseado no protagonismo ${ }^{1}$
}

\author{
Elisângela F. de Mello ${ }^{1}$ \\ Adriano C. Teixeira ${ }^{2}$ \\ ${ }^{1}$ Centro de Referência de Literatura e Multimeios - Universidade de Passo Fundo (UPF) \\ ${ }^{2}$ Curso de Ciência da Computação/Programa de Pós-graduação em Educação - \\ Universidade de Passo Fundo (UPF) \\ \{elisffm,teixeira\}@upf.br
}

\begin{abstract}
This paper aims to present a methodology for digital inclusion developed at the University of Passo Fundo, which provides to the involved people the establishment of communicative and interactive processes with a view to the development of a network culture and critical and creative appropriation of digital technologies. For so, reports the experiment conducted in the year of 2007 at the workshops, computer and citizenship of the Effort for Digital Inclusion. This process was developed with students deprived of primary education of the stateteaching network of Passo Fundo - RS.
\end{abstract}

Resumo. Este texto tem por objetivo apresentar uma metodologia de inclusão digital desenvolvida na Universidade de Passo Fundo que possibilitou aos envolvidos o estabelecimento de processos comunicativos e interativos com vistas ao desenvolvimento de uma cultura de rede e à apropriação crítica e criativa das tecnologias digitais. Para tanto, relata a experiência realizada no ano de 2007 nas oficinas de informática e cidadania do Mutirão pela Inclusão Digital. Tal processo desenvolveu-se com alunos carentes do ensino fundamental da rede estadual de ensino de Passo Fundo - RS.

\section{Alguns elementos introdutórios}

A exclusão digital contribui significativamente para a exclusão social e é um problema que pode passar despercebido em meio a tantos outros que são gritantes na sociedade como fome, violência, desemprego e analfabetismo. Entretanto, a exclusão digital pode ser tratada junto com os demais problemas e sua solução, supõe-se, que pode até mesmo contribuir para a diminuição da exclusão social no país.

Acredita-se que através de projetos educativos é possível incluir social e digitalmente. Todavia, com o avanço tecnológico da era digital, estas iniciativas precisam ser estruturadas a partir de um objetivo maior.

Percebe-se que muitos projetos têm a finalidade de preparar jovens e adultos para o mercado de trabalho, contribuindo dessa maneira para a diminuição do desemprego no

\footnotetext{
${ }^{1}$ Artigo publicado no SBC 2008
}

V. 6 № 1, Julho, 2008 
país, já que a maioria das empresas solicita que seus funcionários tenham domínio da informática, conseqüentemente estas iniciativas amenizam parte do problema e propiciam uma forma de inclusão social. Entretanto, Serpa (2004, p. 183) chama a atenção para o fato de que a "inclusão social não é mais a formação do indivíduo cidadão, incluído na cultura nacional e, sim, do indivíduo consumidor, participante desse não-lugar, o Mercado". Ou seja, existe uma instrumentalização para que se possa servir ao mercado, e não para que se possa exercer a cidadania.

A partir desta reflexão e considerando que grande parte da população tem acesso às tecnologias dentro de instituições de ensino, formais ou não, é possível vislumbrar uma situação mais complexa. Enquanto alunos de escolas particulares têm acesso à informática desde os primeiros anos e em uma dinâmica de autoria, muitas das escolas públicas não possuem estrutura para viabilizar aulas em ambientes com computadores, e as que possuem tal recurso, geralmente o utilizam como espaços de treinamento em determinada tecnologia, sob o discurso de preparar para o mercado de trabalho.

Assim, intui-se que o grande desafio seja propiciar a esta parcela da população o acesso qualificado ao mundo digital, o que se transforma em uma questão estratégica e fundamental para que se possa pensar em um processo efetivo de inclusão social em uma sociedade profundamente modificada pelo advento das tecnologias.

Nas oficinas de Inclusão Digital e Cidadania oferecidas pela Universidade de Passo Fundo acredita-se que incluir digitalmente não é uma questão de possibilitar somente o acesso às Tecnologias de Rede (TR) a determinadas camadas da sociedade. Entende-se que os beneficiários, para serem considerados incluídos digitais, devem assumir uma postura de emissores na rede. Assim, as TR serviriam como ferramentas para que os participantes reconstruíssem suas idéias, para que compartilhassem informações e estabelecessem uma rede colaborativa de aprendizagem.

Neste sentido, este artigo se debruça sobre um dos cinco desafios da Computação no Brasil: o acesso participativo e universal do cidadão brasileiro ao conhecimento, cujo objetivo é

vencer essas barreiras, por meio da concepção de sistemas, ferramentas, modelos, métodos, procedimentos e teorias capazes de endereçar, de forma competente, a questão do acesso do cidadão brasileiro ao conhecimento. Este acesso deve ser universal e participativo, na medida em que o cidadão não é um usuário passivo, o qual recebe informações, mas também participa da geração do conhecimento. (SBC, 2006, p. 17).

\section{Observando o contexto}

A situação observada em Passo Fundo nas escolas públicas de periferia com as quais se realizou esta experiência, é que os alunos não possuem uma formação baseada no uso de recursos multimidiais e pouco utilizam esses recursos em suas escolas. 
Entretanto, mesmo com a implantação de laboratórios de informática nas escolas municipais ${ }^{1}$, as escolas estaduais, em sua maioria, continuam sem acesso aos recursos. Frente a esse problema, optou-se por realizar o processo de inclusão digital de duas turmas de $4^{\mathrm{a}}$ série do ensino fundamental, formadas por estudantes carentes de escola pública estadual. Os alunos tinham entre 10 e 12 anos e estavam acostumados com uma prática tradicional de ensino baseada na transmissão e recepção de informação. Contudo, os alunos não tinham um comportamento pacífico em sala de aula, devido a problemas familiares, de aprendizagem e de auto-estima. Dessa forma, expressavam seus problemas através de agressões físicas, verbais ou ainda, se excluindo das atividades com o argumento de que não sabiam realizá-las.

Outro ponto observado antes de iniciarem os encontros do Mutirão pela Inclusão Digital $^{2}$ foi a verificação do acervo disponível na biblioteca da escola, bem como o acesso e a utilização de tal espaço pelos alunos e professores. A análise era importante porque o objetivo das oficinas não era simplesmente permitir o acesso destes alunos à tecnologia; em decorrência da parceria entre o Curso Ciência da computação ${ }^{3}$ e do Centro de Referência de Literatura e Multimeios ${ }^{4}$, que já tinham objetivos individuais; almejavase com esta proposta que os alunos fossem leitores de diferentes tipos de texto e que se tornassem protagonistas em diferentes ambientes.

Foi observado que o acervo da biblioteca da escola participante do projeto era formado em sua maioria por livros didáticos. Existiam poucos exemplares de livros de literatura e não existiam periódicos, histórias em quadrinhos, músicas e filmes no acervo. Também não havia nenhum computador, somente uma televisão e um vídeo-cassete, que os professores poderiam utilizar quando locavam filmes para as suas aulas. Outro fator identificado é que, por falta de funcionários e professores, a biblioteca ficava a maioria do tempo fechada, o que dificultava o empréstimo de livros e permitia somente a leitura de textos estudados em sala de aula.

Considerando tal contexto, montaram-se os encontros das oficinas do Mutirão pela Inclusão Digital especificamente para o grupo em questão. Semanalmente, durante três horas, alunos e professoras das turmas envolvidas, através da apropriação dos recursos tecnológicos, estabeleciam contato com a literatura em diferentes suportes. Em cada encontro, um tema ligado à realidade do grupo era abordado, indicava-se, de acordo com o tema, a leitura de textos e criava-se um espaço para que o grupo opinasse sobre as leituras realizadas e o tema desenvolvido.

A estratégia utilizada tinha como intuito quebrar a rotina de sala de aula, suscitar a vontade de ler novos textos após o contato com os livros e, quem sabe, despertar o potencial autoral dos alunos.

\footnotetext{
${ }^{1}$ Destaca-se que no ano de 2007 a Prefeitura Municipal de Passo Fundo, contou com aporte financeiro federal para instalar 10 laboratórios de informática e, em 2008, foi disponibilizado recurso para mais 18.

Mais infromações em: http://inf.upf.br/ mutirao. Acesso em 8 de maio de 2008 .

Mais infromações em: httt://inf.upf.br/ mutirao. Acesso em 8 de maio de 2008.
Mais infromações em: www.upf.br/computacao. Acesso em 8 de maio de 2008.

4 Mais infromações em : http://mundodaleitura.upf.br. Acesso em 8 de maio de 2008.

V. 6 № 1, Julho, 2008
} 


\section{A escolha do software para as oficinas}

Ao criar as oficinas, também se pensou no software a ser utilizado durante o projeto. A dinâmica colaborativa da oficina não mudaria com o uso de um software proprietário, porém, um dos objetivos era romper a perspectiva de consumo e de dependência tecnocultural. Então, não se via porque motivar o uso de um software proprietário, seria interessante apostar em um software com custo inferior, qualidade semelhante, mas que ao mesmo tempo pudesse ser utilizado livremente pelos alunos e pela própria escola.

Outra razão importante na escolha do software, foi o próprio conceito utilizado de inclusão digital, em uma perspectiva não apenas de acesso, mas de ambiente colaborativo onde os envolvidos têm liberdade para expressar seus pensamentos e opiniões. Neste sentido, era igualmente significante utilizar um software que tivesse filosofia semelhante aos princípios do projeto.

Verificou-se a necessidade conceitual de utilizar o software livre nas oficinas, uma vez que o que estava em jogo era a questão da autoria, da partilha, da cooperação e da colaboração. Acerca desta natural e necessária relação entre inclusão digital e software livre, Silveira argumenta

Em síntese, é fundamental integrar a política de inclusão digital, de informatização das escolas e das bibliotecas públicas e a adoção de TI como instrumento didático-pedagógico à estratégia de desenvolvimento tecnológico nacional. Este é um dos argumentos para o uso do software livre nas políticas de inclusão digital. (2003, p.41)

Certamente, esta opção não estava baseada única e exclusivamente no fomento do desenvolvimento tecnológico nacional, ou ainda, em uma percepção superficial de que basta utilizar software livre para fazer inclusão digital. A opção pela utilização desta modalidade de software buscava, principalmente, "estabelecer sistemas e métodos que sustentem a constituição de uma cultura digital para acesso do cidadão ao conhecimento, respeitando sua diversidade e diferenças.” (SBC, 2006, pág. 18).

Uma das motivações mais freqüentes para a não utilização de software livre em ambientes educacionais, está comumente relacionada à exígua existência de softwares educacionais suportados por este sistema operacional. Ou ainda, à pretensa dificuldade que a mudança de interface traria à utilização. Neste sentido, o Curso de Ciência da Computação da Universidade de Passo Fundo, decidiu pela criação de uma distribuição Linux, denominada Kit Escola Livre - Kelix ${ }^{5}$, que contasse com uma coletânea de jogos

\footnotetext{
5 Mais informações em: http://kelix.upf.br
}

V. 6 № 1, Julho, 2008 
educacionais catalogados e categorizados por disciplina $^{6}$, o que aumenta significativamente o potencial educacional do Linux e o faz uma excelente opção, também pedagógica, para instituições de ensino formais ou não (Figura 1).

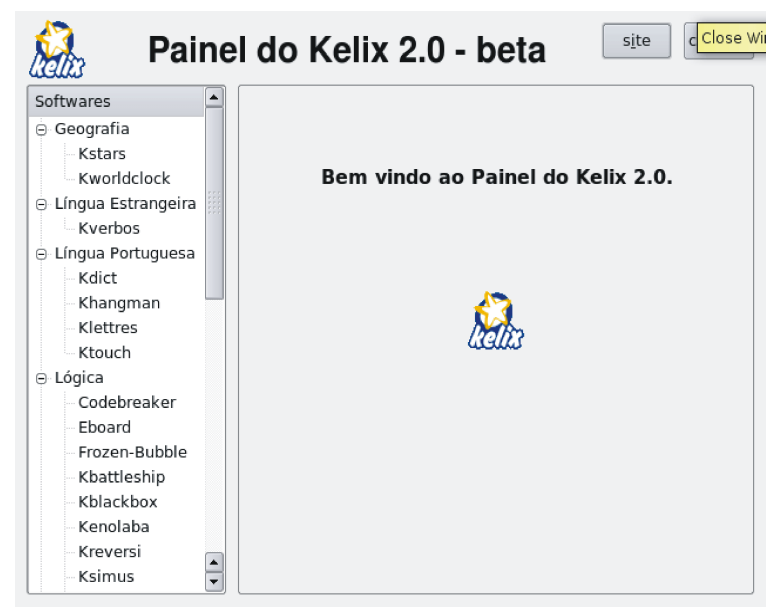

Figura 1. Painel do Kelix

Em função da facilidade de sua interface, projetada especificamente para iniciativas de inclusão digital e software livre, e pelo caráter livre de distribuição, era possível disponibilizar cópias do Kelix a todos que solicitassem, professores, alunos ou comunidade, para que pudessem conhecê-lo em máquinas que não as utilizadas nas oficinas. Na época, a Prefeitura Municipal de Passo Fundo havia recebido verba federal para a informatização das escolas públicas e, ao montar os laboratórios das escolas, fez a opção pelo Kelix como sistema operacional padrão dos equipamentos.

Com relação à utilização do sistema nas oficinas, observou-se que pelo fato de o mesmo ser desenvolvido por um grupo de estudo da própria universidade, contava-se com o pronto suporte ao sistema e com a possibilidade de fazer alterações na distribuição, a fim de a atender às especificidades do grupo com que se estava trabalhando e às necessidades das oficinas, processos extremamente complexos para softwares proprietários.

Considerando-se que nem todos os estabelecimentos sócio-educativos possuem recursos financeiros para a regularização de software, outro elemento determinante na adoção desta solução, ou semelhantes, em iniciativas de inclusão digital, reside no fato de que é possível utilizar os programas disponíveis sem se preocupar com todos os processos legais inerentes a um software proprietário. Neste sentido, Silveira aponta que "os recursos economizados com as licenças de propriedade podem ser empregados em formação, treinamento e educação digital." (2003, p.41) .

O simples fato de desenvolver softwares com o código aberto já é uma ação significativa de exercício da cidadania. Quando este é compartilhado e aprimorado por diferentes pessoas, passa a ser uma maneira de quebrar as barreiras impostas pelas

\footnotetext{
6 Mais informaç̃es sobre o Kelix e seu funcionamento em: TEIXEIRA, A.C. Kit Escola Livre: A indissociabilidade entre inclusão digital e software livre na sociedade contemporânea. In: SBC. (Org.). XVII Simpósio Brasileiro de Informática na Educação. Brasília DF: Gráfica e Editora Positiva LTDA, 2006, v. I, p.
}

V. 6 № 1, Julho, 2008 
grandes empresas de software. Criar coletivamente, com custo reduzido, algo criativo e bem elaborado é um meio de facilitar que mais pessoas tenham acesso às tecnologias da informação e comunicação.

Desta forma, o software livre é um instrumento de inclusão digital. Em um país em que muitos vivem na linha da pobreza, a concentração de programadores em torno de um projeto que está voltado à diminuição de gastos demonstra solidariedade para com o país, pois quanto mais acessíveis, mais haverá apoiadores aos projetos de inclusão e promoção da educação.

$\mathrm{O}$ acesso à informação deve estar dissociado da compra de equipamento. O aprendizado, por sua vez, deve acontecer em uma dinâmica horizontal, aberta, reticular e colaborativa, podendo ser potencializado pelas tecnologias da informação e comunicação. Neste sentido, Silva salienta que

\begin{abstract}
Aprender com o movimento das novas técnicas é antes de tudo aprender com a nova modalidade comunicacional. Ou seja: aprender que comunicar não é apenas transmitir, mas disponibilizar múltiplas disposições à intervenção do interlocutor. A comunicação só se realiza mediante a sua participação, isso quer dizer bidirecionalidade, intervenção na mensagem e multiplicidade de conexões. $(2002$, p.69)
\end{abstract}

\title{
4. Oficinas de Informática e Cidadania
}

Participar da Sociedade da Informação é direito de todos. Sua democratização deve possibilitar que toda a população tenha acesso às novas tecnologias, utilizando-as em todo o seu potencial, incluindo o acesso à rede mundial, mas também permitindo uma prática de transformação da sociedade e melhoria das condições de uma determinada região, comunidade ou grupo.

As oficinas de Informática e Cidadania fazem parte do rol de ações do projeto de Assistência Social Mutirão pela Inclusão Digital da Universidade de Passo Fundo. As oficinas têm como objetivo a vivência de uma dinâmica de inclusão digital, entendida como

um processo horizontal que deve acontecer a partir do interior dos grupos, com vistas ao desenvolvimento de cultura de rede, numa perspectiva que considere processos de interação, de construção de identidade, de ampliação da cultura e de valorização da diversidade, para, a partir de uma postura de criação de conteúdos próprios e de exercício da cidadania, possibilitar a quebra do ciclo de produção, consumo e dependência tecnocultural. (Teixeira, 2005, p. 31).

O módulo das oficinas destinados a alunos carentes da rede pública da periferia, em especial do bairro São José, onde está situada a Universidade de Passo Fundo, busca a formação de leitores de diferentes mídias que, ao vivenciarem esta experiência, podem superar a postura instituída de receptores e se tornarem transmissores de informações, 
sentidos e significados, assumindo a centralidade de processos em uma dimensão hipertextual.

Para os envolvidos no projeto, professores, colaboradores, alunos da Ciência da Computação, incluir digitalmente não é apenas ensinar a utilizar pacotes de programas, a questão da inclusão está ligada a ser leitor-autor. Pierre Lévy (1999, p. 238) ressalta que

\begin{abstract}
(...) não basta estar na frente de uma tela, munido de todas as interfaces amigáveis que se possa pensar, para superar uma situação de inferioridade. É preciso, antes de mais nada, estar em condições de participar ativamente dos processos de inteligência coletiva que representam o principal interesse do ciberespaço.
\end{abstract}

Foram realizados 18 encontros, com 51 alunos carentes da $4^{\mathrm{a}}$ série do ensino fundamental que tinham entre 10 e 12 anos. Em decorrência do histórico de submissão da maioria das crianças, ao chegarem ao primeiro encontro, demonstravam medo de não saberem utilizar os recursos, vergonha de dizer que não dominavam a nova tecnologia e, para completar, receio de danificar o equipamento, porque as professoras alertavam que os alunos tinham de tomar cuidado para não mexerem em nada, sem antes perguntar, pois se "apertassem" em algo errado poderiam estragar os computadores. Apesar de todos esses empecilhos, o que mais se destacou no primeiro encontro foi a vontade de utilizarem o computador: todos estavam curiosos e ansiosos para conhecer os recursos.

Os alunos estavam acostumados com uma prática pedagógica onde o professor seria protagonista e os educandos espectadores. Verificou-se que antes de acontecer uma mudança de postura, era importante resgatar a identidade dos participantes, pois muitos não conheciam a história de sua família e estavam numa situação de exclusão social, freqüentemente, expressavam verbalmente que não eram capazes, e tinham receio de expressar opiniões com medo de errar.

Em virtude do contexto já descrito, o grupo teve de começar quase do zero: eles não usavam computador e também não eram leitores; conheciam poucos autores, tinham dificuldades na escrita e estavam acostumados ao ensino tradicional e verticalizado. Mas, daquele momento em diante, estavam participando de um projeto que tinha ênfase na utilização do computador; onde eram falados e lidos diferentes tipos de textos com a apresentação do nome dos autores de cada texto, e todos eram instigados a colaborar, demonstrar opinião e contribuir para que se estabelecesse uma rede, tendo em vista a construção de um processo participativo de conhecimento.

As oficinas tinham o tema geral "Dilemas da Hipermodernidade" e elas foram estruturadas de maneira que os beneficiários colaborassem em blogs, chats, fóruns, conversas presenciais, criação de textos e desenhos, sendo, assim, protagonistas no ciberespaço.

Então, para aproximar o grupo e motivá-lo a colaborar nos encontros, foram indicadas leituras e propostas atividades que suscitassem conversas em que todos pudessem participar, sem se sentir constrangidos. Os primeiros encontros estavam focados na subjetividade dos alunos, com a finalidade de resgatar sua identidade e 
mostrar-lhes a importância de sua participação, em outras palavras, eles precisavam se sentir parte do todo. Morin destaca

O mundo torna-se cada vez mais um todo. Cada parte do mundo faz, mais e mais, parte do mundo e o mundo, como um todo está cada vez mais presente em suas partes. Isto se verifica não apenas nas nações e povos, mas para os indivíduos. (2002, p.67)

Semanalmente, procurava-se ressaltar as qualidades individuais, inclusive motivando as crianças a indicarem a importância de cada colega na turma. A atividade contribuiu para criar e fortalecer laços de amizade dentro do grupo. A partir do momento em que os alunos começaram a se sentir pertencentes ao grupo e importantes, eles perdiam o medo de se expor e se estabelecia uma rede de troca de conhecimentos. Receio, medo de errar, dificuldade de expressar opiniões e timidez, tudo isso desapareceu quando os alunos navegaram na rede e no lugar surgiu uma nova postura. Antes, era um grupo de receptores, após alguns encontros, eles já eram crianças participativas, que colaboravam em chats, fóruns, blogs e que trocavam e-mails com grande entusiasmo.

Depois dos encontros de resgate da identidade; onde foi desenvolvido um trabalho de valorização do colega, da família, da importância da cultura de cada um, e da participação deles na escola e na comunidade; centrou-se a discussão em torno dos problemas sociais da comunidade e o envolvimento deles em relação às situações lançadas pelo grupo.

É necessário ressaltar que a postura dos responsáveis pelas oficinas era a de mediadores: indicavam textos, propunham atividades, instigavam conversas, porém, a triagem e a solução para os problemas eram realizadas pelos alunos. Os debates aconteciam na rede, a tecnologia tornou-se o meio de compartilhamento de informações, tomada de decisões, expressão de sentimentos e divertimento.

Entretanto, além das oficinas buscarem o resgate da identidade, fazendo com que os alunos se sentissem parte do todo, criando um ambiente colaborativo para troca de conhecimento, tinha-se a preocupação com a leitura de diferentes tipos de textos e que estes pudessem contribuir para a formação de novos leitores. Porém, não se queria que esses leitores apenas decodificassem os textos, mas que fossem capazes de entendêlos, conversar sobre eles e estabelecer relações com outros textos. Buscava-se por um novo leitor, denominado de leitor-autor. Sobre esta perspectiva, Silva aponta que:

A participação do aluno se inscreve nos estados potenciais do conhecimento arquitetados pelo professor de modo que evoluam em torno do núcleo preconcebido pelo professor como coerência e continuidade. $\mathrm{O}$ aluno não está mais reduzido a olhar, ouvir, copiar e prestar contas. Ele cria modifica, constrói, aumenta e, assim, torna-se co-autor, já que o professor configura o conhecimento em estados potenciais. (Silva, 2002, p.191)

Fomentar este crescimento dos alunos não foi algo que aconteceu de uma oficina para outra. $\mathrm{O}$ trabalho foi desenvolvido durante um ano e a mudança de postura das crianças, de receptores para protagonistas, só foi observada após um mês de 
oficinas. Nos quatros primeiros encontros elas ainda se sentiam receosas, não tinham autonomia para utilizar os recursos e ficavam inibidas ao exporem suas opiniões. Após saberem que eram aceitas no grupo, que os colegas gostavam delas, e de escutarem que estavam nas oficinas para participar, aprender e que era importante todos contribuírem para enriquecer as atividades, o grupo começou a ter mais liberdade e autonomia, então, qualquer tema proposto era pesquisado e discutido por eles sem dificuldade.

As atividades proporcionaram aos envolvidos a postura de protagonistas. Foi quebrada a dinâmica de um para todos, ou seja, um protagonista emitir informações para o restante do grupo, e se consolidou uma estrutura reticular, onde cada integrante tinha liberdade para emitir opiniões. Aproximar o tema das oficinas com a realidade do grupo envolvido proporcionou que eles se sentissem integrantes de uma rede. Assumindo-se como co-responsáveis pelas atividades, começaram a perceber que só teriam informações para discutir e colaborar se lessem os textos, pesquisassem sobre o assunto, ou seja, precisavam estar presentes, participando buscando informações para ocorrer comunicação entre eles.

Os monitores da oficina eram elos de ligação, estavam no ambiente para orientar e motivar as atividades, mas cada aluno tinha a liberdade para expor idéias, navegar na rede, concordar ou discordar das atividades propostas. Assim, a construção do conhecimento ia acontecendo colaborativamente, no ritmo do grupo. E ao demonstrarem que tinham esgotado as possibilidades de interação sobre determinado tema, o monitor lançava novas idéias ou sugeria outras atividades. Tal postura dos monitores, colocava em prática as sugestões que Silva considera importantes na postura de um professor:

O professor não transmite o conhecimento. Ele disponibiliza domínios de conhecimento de modo expressivamente complexo e, ao mesmo tempo, uma ambiência que garante a liberdade e a pluralidade de expressões individuais e coletivas. Os alunos têm aí configurado um espaço de dialogo, participação e aprendizagem. (2002, p.185)

Como o autor descreve, concretizou-se nas oficinas um espaço de aprendizagem. A adesão das crianças foi total: todos queriam participar, traziam de casa endereços de sites para visitarem, queriam utilizar os recursos e aproveitar todo o tempo possível das oficinas para estarem conectados, demonstravam-se empolgados em enviar e-mails e postar mensagens nos blogs. Ficavam curiosos para ler o que o colega havia postado no blog, ansiosos para saber se o e-mail já tinha chegado ao seu destino, e felizes ao receberem respostas de suas mensagens.

Ao final de cada oficina, os responsáveis realizavam uma avaliação de todas atividades realizadas durante as três horas que o grupo havia vivenciado as atividades. Observava-se como as crianças haviam interagido, as dificuldades encontradas, o que haviam gostado, o que não havia funcionado e os avanços percebidos durante as semanas. Com base nestas observações, constatou-se que os alunos tornaram-se mais participativos e responsáveis. 
No início, quando eram sugeridas atividades para serem realizarem durante a semana, como pesquisa de um tema ou a leitura de um texto, a maioria não trazia. Posteriormente, percebeu-se que além de trazerem o solicitado, eles anotavam endereços de sites para navegaram, faziam pesquisas de interesse familiar, procuravam mais sobre os programas televisivos, e trocavam, entre eles, informações de interesse comum.

Também foi verificado que na participação em $b \log s$, fóruns e até mesmo no envio de e-mails houve um crescimento. Primeiramente, as frases eram curtas, muitas vezes sem início, meio ou fim, algumas fora de contexto e sem continuidade. Depois, foi percebido que as frases foram aumentando em quantidade e qualidade. Os alunos passaram a escrever com mais coerência e conseguiam se expressar em pequenos textos. Aos poucos, todos perceberam que estavam fazendo parte de algo maior, quando acessavam sites de autores, de empresas, ou governamentais e depois voltavam para expor idéias no blog, viam que tudo estava no mesmo "lugar" e que todas pessoas que estavam conectadas podiam ler o que eles haviam escrito. Isso despertou um interesse maior em ler as opiniões dos colegas e de também de divulgarem o que haviam realizado.

Sem dúvida, o fascínio em enviar e receber e-mails foi a atividade que mais se destacou. Até mesmo nos momentos destinados somente para jogarem ou navegarem em sites de interesse individual, as crianças optavam por ocupar o tempo enviando $e$ mails para os colegas de aula e para familiares que residiam em outras cidades. No entanto, o e-mail não era escrito sem se preocuparem com o aspecto formal, eles dedicavam o tempo escrevendo com diferentes cores, cuidando para escreverem as palavras corretas e colocavam imagens para deixar a mensagem mais interessante.

A dinâmica das oficinas, que a cada semana abordava um tema, permitiu que a leitura de contos, poesias, histórias em quadrinhos, charges, lendas se tornasse mais interessante. Cada tema tratado (Eu e a minha família, Eu e a minha escola, Eu e os meus amigos, Eu na comunidad, e Eu no mundo) foi desenvolvido com um recurso ou estratégia diferente (música, contação de histórias, filmes, brincadeiras ou debates). O computador, neste caso, foi o meio que eles tinham para exercerem a autoria. A partir das atividades vivenciadas, eles criavam histórias, escreviam sobre o que mais gostavam, modificavam o final, relacionavam os textos com a realidade em que viviam e achavam soluções para melhorar seu contexto. Ou seja, reconheciam seu potencial autoral e sua responsabilidade social.

\section{Considerações finais}

A liberdade do software livre reforça os direitos dos cidadãos e a liberdade de criar. Neste projeto, a opção pelo software se deu pela questão do livre acesso e da filosofia de liberdade que o norteia. Utilizou-se o Kelix em todas as oficinas e ele sempre foi bem aceito pelo grupo e adequado para realizar as atividades. As crianças não eram usuárias do computador e passaram a utilizar as ferramentas sem dificuldades e sem dependência de um software específico. Inclusive, após se sentirem seguros, eles 
utilizavam computadores que tinham outros softwares em outros locais e não sentiam dificuldades para interagir.

O objetivo de incluir digitalmente os envolvidos e promover a leitura aconteceu gradativamente em uma dinâmica de troca de informações através de um suporte tecnológico ou de um professor que desafiou a construção do conhecimento. Foi significativo acompanhar a mudança de postura dos alunos para com os colegas, que trocaram as brincadeiras de subestimar e inferiorizar e optaram por valorizar o outro, dialogar e compartilhar novidades.

A liberdade de expor opiniões, a sensação de responsabilidade pelo grupo, o respeito ao próximo e a contribuição de cada um para que todas as atividades acontecessem reforçavam a dinâmica de rede. O relacionamento estabelecido viabilizou o despertar da consciência cidadã e da autonomia na busca do conhecimento.

\section{Referências}

Lévy, P. "Cibercultura." São Paulo: Editora 34, 1999.

Morin, E. "Os sete saberes necessários à educação do futuro." 8. ed. São Paulo: Cortez, 2003.

Roger, C. "A aventura do livro: do leitor ao navegador.” São Paulo: UNESP, 1998.

SBC. "Grandes Desafios da Pesquisa em Computação no Brasil” - 2006 - 2016. São Paulo: SBC, 2006.

Serpa, Felippe. "Rascunho digital: diálogos com Felippe Serpa". Salvador: Udufba, 2004.

Silva, M. "Sala de aula interativa". 2.ed. Rio de Janeiro: Quartet, 2002.

Silveira, S. A. “Software livre e inclusão digital.” São: Conrad editora do Brasil, 2003.

Teixeira, A.C. "Formação Docente e Inclusão Digital: a análise do processo de emersão tecnológica de professores". Tese (Doutorado em Informática na Educação) - Programa de Pós Graduação em Informática na Educação da Universidade de Federal do Rio Grande do Sul, Rio Grande do Sul, 2005. 